\title{
Focal fat mimicking multiple hepatic metastases on FDG PET/CT imaging
}

\author{
Maurice H. Zissen • Andrew Quon
}

Received: 13 April 2009/Accepted: 28 April 2009 /Published online: 27 June 2009

(C) Springer-Verlag 2009

FDG PET/CT imaging is commonly used for the detection of metastatic disease within the liver [2]. Its use has been suggested in the setting of hepatic steatosis due to a decrease in false-positive 'pseudotumor' findings commonly seen on sonographic and CT imaging as a result of areas of focal fat sparing [3]. While benign hepatic lesions such as granulomatous abscesses and focal nodular hyperplasia have been shown to concentrate FDG, steatosis is typically associated with decreased FDG activity and can be recognized on the basis of periportal distribution [1,4]. Here we present the case of a 48-year-old woman with infiltrating ductal carcinoma of the right breast with metastatic disease in 11 axillary lymph nodes found during axillary node dissection. Subsequent PET/CT scanning identified five low-density, intensely FDG-avid hepatic foci with standardized uptake values (SUV) in the range 4.2-7.3 that were presumed to represent metastases (panels a-c). The patient was treated with chemotherapy and chest wall radiation. PET/CT after six cycles of chemotherapy did not show significant change in the liver lesions and was otherwise negative. CT-guided biopsy of the four largest liver lesions was performed. Pathology results showed macrosteatosis in a background of benign hepatic parenchyma, without inflammatory cells or neoplastic infiltrates (panel d). Follow-up PET/CT after 13 months showed the same five foci of focal steatosis with similar size, shape and FDG uptake that strikingly mimic the appearance of hepatic metastases.

\footnotetext{
M. H. Zissen · A. Quon $(\bowtie)$

Department of Radiology, Division of Nuclear Medicine,

Stanford University Medical Center,

300 Pasteur Dr, H0101 MC 5281,

Stanford, CA 94305, USA

e-mail: aquon@stanford.edu
}

M. H. Zissen • A. Quon

Molecular Imaging Program at Stanford (MIPS),

Stanford University Medical Center,

Stanford, CA, USA

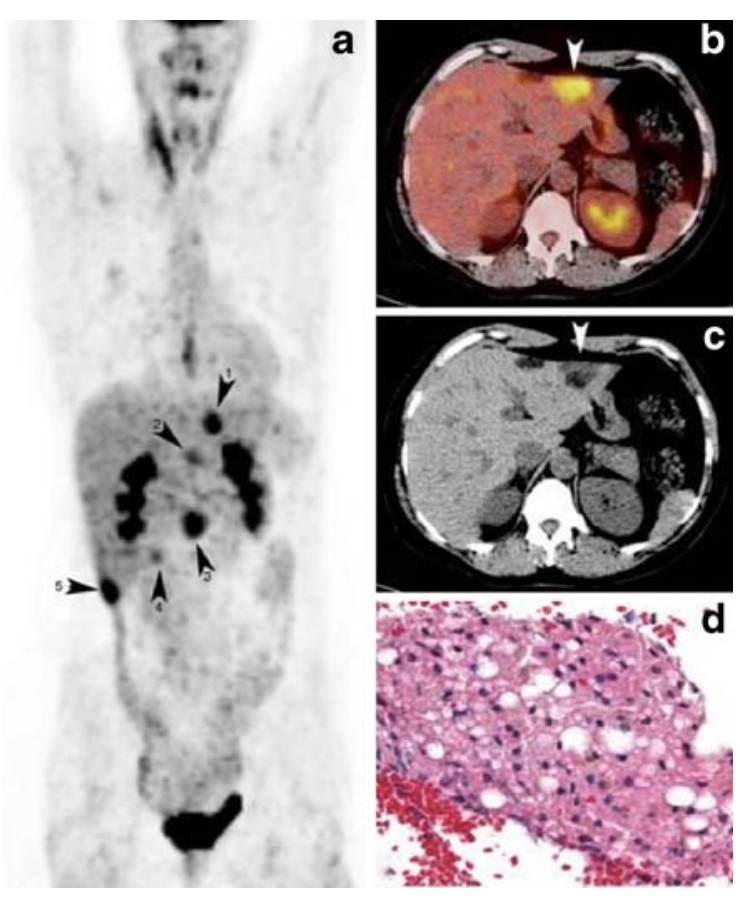

Acknowledgments We would like to thank Dr. Juliet Kral for her help with manuscript preparation.

\section{References}

1. Aznar DL, Ojeda R, Garcia EU, Aparici F, Sánchez PA, Flores D, et al. Focal nodular hyperplasia (FNH): a potential cause of false positive positron tomography. Clin Nucl Med 2005;30:636-7. doi: 10.1097/01.rlu.0000174209.49753.a5.

2. Delbeke D, Martin WH, Sandler MP, Chapman WC, Wright JK Jr, Pinson CW. Evaluation of benign versus malignant hepatic lesions with positron emission tomography. Arch Surg 1998;133:510-5. doi: 10.1001/archsurg.133.5.510.

3. Chong VF, Fan YF. Ultrasonographic hepatic pseudolesions: normal parenchyma mimicking mass lesions in fatty liver. Clin Radiol 1994;49:326-9. doi: 10.1016/S0009-9260(05)81798-2.

4. Prasad SR, Wang H, Rosas H, Menias CO, Narra VR, Middleton WD, et al. Fat-containing lesions of the liver: radiologic-pathologic correlation. Radiographics 2005;25:321-31. doi: 10.1148/rg.252045083. 